\title{
Partial price discrimination by an upstream monopolist
}

\author{
Lluís Bru • Ramon Faulí-Oller • Joel Sandonís
}

Received: 25 September 2008 / Accepted: 20 April 2010 / Published online: 21 August 2010 (C) The Author(s) 2010. This article is published with open access at Springerlink.com

\begin{abstract}
We analyze third degree price discrimination by an upstream monopolist to a continuum of heterogeneous downstream firms. The novelty of our approach is to recognize that customizing prices may be costly. As a consequence, partial price discrimination arises in equilibrium; in particular, we show that inefficient downstream firms receive personalized prices whereas efficient firms are charged a uniform price. The extreme cases of complete price discrimination and uniform price arise in our setting as particular cases, depending on the cost of customizing prices.
\end{abstract}

Keywords Price discrimination · Input markets

JEL Classification $\quad$ D4 $\cdot \mathrm{L} 11 \cdot \mathrm{L} 12$

We thank the editor, Pedro Mira and two anonymous referees for very helpful advice. We also thank Aleix Calveras, Daniel Cardona-Coll, María Paz Espinosa, Angel Hernando, Inés Macho-Stadler, David Pérez-Castrillo and Juana Santamaría for their comments. Financial support from SEJ 2004-02172, SEJ 2007-67895, SEJ 2007-62656, FEDER funds and the IVIE is gratefully acknowledged.

L. Bru

Departament d'Economia del'Empresa, Universitat de les Illes Balears,

Campus de la carretera de Valldemossa km. 7.5, 07122 Palma de Mallorca, Spain

e-mail: lluis.bru@uib.es

R. Faulí-Oller · J. Sandonís (凶)

Departament de Fonaments del'Anàlisi Econòmica, Universitat d'Alacant,

Campus de Sant Vicent, 03071 Alacant, Spain

e-mail: sandonis@merlin.fae.ua.es

R. Faulí-Oller

e-mail: fauli@merlin.fae.ua.es 


\section{Introduction}

In this paper, we analyze third degree price discrimination by an upstream monopolist. Third degree price discrimination can be defined as the possibility to charge different linear prices to different (groups of) customers. In order for price discrimination to be feasible, it must be possible to separate different (groups of) customers, which is called market segmentation. The seller must also be able to keep resales from occurring. There has been a long debate on the competitive effects of price discrimination. The Robinson-Patman Act, for example, makes it unlawful to discriminate in price between different purchasers if the effect of the discrimination may substantially lessen competition or create a monopoly.

Many papers have studied the welfare effects of price discrimination. For the case of final good markets we can mention, among others, Robinson (1933), Schmalensee (1981), Varian (1980) and Schwartz (1990). However, as Yoshida (2000) recognizes "the vast majority of legal and other policy disputes over price discrimination concern input markets, not final good markets". Then, it seems important to analyze cases where the discriminating monopolist is an input supplier and the buyers are downstream firms producing a final good. In this setting, Katz (1987) and DeGraba (1990) show that price discrimination lowers welfare, because low cost downstream firms are charged higher prices. Total output, however, does not change as a consequence of price discrimination. Yoshida (2000) constructs a model where total output does change and obtains the counterintuitive result that an increase in total output is a sufficient condition for a welfare decrease.

New information technologies facilitate implementing price discrimination, because they allow firms to obtain personalized information about customers. These technologies are used in intermediate markets in the relationship between suppliers and retailers and also in final markets in the relationship between retailers and consumers. Concerning the first case, tags attached to products allows an accurate tracking of each particular good allowing to know how it goes along the value chain from the production plant to the warehouse, an from the warehouse to the supermarket. Accurate tracking allows to improve distribution reducing for instance inventory costs.

Concerning final markets an example of the introduction of new technologies would be the new uses of loyalty cards by supermarkets. Each time the card is swiped at the point of sale the content of the purchase can be incorporated into the information record about the customers. This allows retailers to target customers with personalized prices. Another example would be an internet store that uses consumer tracking technologies such as clickstream tracking, on-line registration, and cookies. Selling on the Internet with such technologies enables a firm to better understand each individual customer's tastes and to offer individualized prices (see Chen 2006). In fact, there is an entire industry known as "yield management" that charges firms for specialized consulting and software to help them implement price discrimination. ${ }^{1}$

The introduction of these new technologies can be useful for the business strategy of firms, improving productivity, allowing price discrimination, but must be

\footnotetext{
1 The example on tags is extracted from The Economist, "The future is still smart", June 24th 2004. Examples of loyalty cards and tracking technologies are further discussed in Shapiro and Varian (1999).
} 
accompanied by investments that can be extremely costly. ${ }^{2}$ Therefore, firms must decide whether to introduce these technologies in their marketing strategies and the intensity of their use.

In the present paper, we study firms' incentives to price discriminate when customizing prices is costly. This introduces an interesting trade-off in the analysis: the gains of price discrimination have to be compared with its costs, which allows us to endogenously determine the extent of price discrimination. Our paper is close in spirit to Liu and Serfes (2004) in the sense that, in both papers, price discrimination involves a costly investment that imposes a trade-off on the decision to price discriminate. However, whereas Liu and Serfes (2004) focus on final good markets we investigate intermediate markets. Moreover, the nature of the investment is very different in the two papers. Whereas in Liu and Serfes (2004) it improves market segmentation, in our paper it is used to customize prices. To the best of our knowledge, this possibility has been neglected so far by the literature.

We consider an upstream monopolist selling an input to a continuum of downstream firms producing a homogeneous good. We assume that downstream firms are heterogeneous in their production cost. Transactions between the upstream supplier and downstream firms can occur either at a common posted price or at a personalized price. The latter option requires a costly specific investment in the form of a link that allows the upstream firm to adjust the supply contract to the individual characteristics of the firms. ${ }^{3}$ In other words, the creation of links allows the upstream firm to price discriminate among its linked customers. Price discrimination is profitable because firms' differences in costs translate into different elasticity of input demands. In particular, it is the case that the higher the cost of a downstream firm the higher its input demand elasticity. Therefore, the upstream firm would like to adjust upwards the wholesale price for low cost firms and downwards for high cost firms, knowing that the personalized contract will only be accepted if it offers a discount with respect to the posted price.

Regarding the creation of links, we will analyze two possible cases: on the one hand, the links are created by the upstream firm in a centralized way; on the other hand, each downstream firm decides whether to establish a link with the upstream firm.

In the first case, the upstream firm prefers to connect high cost firms, because low cost firms would reject the personalized contract whenever the posted price market exists. In the second case, we have that the gains of creating a link for downstream firms are increasing in their costs, because the higher their costs the higher the discount they will receive in the personalized contract. This explains that, again, market is segmented such that high cost firms create links and are treated personally and low cost firms attend the posted price market.

\footnotetext{
2 For example, according to Lieberman $(1991,1993)$ a yield management firm charges upwards of $\$ 10$ million for the software required to implement price discrimination for a single large firm.

3 This cost can represent an investment in a technology that allows for personal communication. It can also include the direct costs associated with tailoring and enforcing a large number of contracts (Lafontaine and Oxley 2004). Or it could also arise as a fee that an intermediary firm charges to connect buyers and sellers.
} 
In both cases, in equilibrium, some firms receive a personalized price while others are supplied at a common price. This is what we call partial price discrimination. The extreme cases of complete price discrimination and uniform pricing, studied in the earlier literature, arise in our setting as particular cases when the cost of the link vanishes and when it is large enough respectively.

Regarding the effect of (partial) price discrimination on social welfare, things are simplified because we get the result that total output does not depend on the distribution of links. Then, (partial) price discrimination only affects total production costs. Given that the upstream firm subsidizes inefficient firms through price discrimination, total cost increases, which reduces social welfare. Therefore, in our context, we could prescribe not to allow for price discrimination. Lafontaine and Oxley (2004) illustrates the existence of partial price discrimination in the franchising industry. They compare the contracting practices of North American franchisors at home and in Mexico and they are able to analyze the extent of contract customization in the foreign market. They find a low use of contract customization and that firms do not adjust their foreign contracts as they accumulate experience in the Mexican market. They conclude that benefits of using different contracts in the two markets must be insufficient to warrant the costs of customization.

In the last section of the paper, we apply the model to a case where the links are provided by an intermediary firm. We can interpret the intermediary as a Business-toBusiness (B2B) firm that allows for online communications and transactions between buyers and sellers in exchange for a per-transaction fee. We consider the case of a nonindustry participant. ${ }^{4}$ Observe that e-commerce is a good illustration of our model, given that price discrimination is a common practice in the Internet. For example, one implication that has already been noticed in the business press is that the extent of the information obtained in Internet opens new possibilities for firms to price discriminate. One very important information that sellers can obtain comes from the past purchase record of their customers ("it [Safeway] uses its website for (...) collecting and mining data on consumer's preferences both from the site and from loyalty cards, so it can personalize promotions" (The Economist, June 24th 1999). Another advantage of Internet is that as communication is personal, price cuts are only observed by targeted sellers. The following quotation of the FTC Report on "Competition Policy in the world of B2B Electronic Marketplaces" clarifies the situation "(...) sellers can customize price lists to reflect agreements reached with specific buyers but ensure that those prices can be viewed only by the intended buyers".

In the paper, we consider that a link between the upstream firm and a particular downstream firm is created only when both of them pay a subscription fee charged by the intermediary firm. We obtain partial price discrimination as the equilibrium outcome of an extended game where the cost of creating a link is endogenously chosen by an intermediary firm. We get, as before, that high cost firms are the ones treated

\footnotetext{
4 In practice, the fast growth of the e-commerce has induced also large firms to organize their own B2B to manage their relationships with customers and suppliers (Milliou and Petrakis 2004). For example, in 1999, Ford and General Motors announced that their huge purchasing operations would be transferred to the web.
} 
personally. Moreover, the burden of the (endogenous) cost of price discrimination mainly falls over the downstream side of the market.

The rest of the paper is organized as follows. In the following section, we present the general model and solve it for the cases where the upstream firm and downstream firms choose the links respectively. In Sect. 3, we apply the model to the case where the links are provided by an intermediary firm. Finally, the last section discusses the results and opens new avenues for future research.

\section{The model}

We assume that there is an upstream monopolist producing an intermediate good at no cost. There also exists a continuum of downstream firms that transform this input on a one-for-one basis into a final homogeneous good. The cost of this transformation for downstream firm $i$ is given by:

$$
C_{i}\left(q_{i}\right)=c_{i} q_{i}+q_{i}^{2}
$$

There is a continuum of downstream firms, heterogeneous in parameter $c_{i}$, which is uniformly distributed in the interval [0,1]. Market demand is given by $P(Q)=A-Q$.

The timing of the game is as follows:

In the first stage, the links are created. We will consider two different possibilities, namely, either they are chosen in a centralized way by the upstream firm or they are decided individually by downstream firms. In any case, the cost of creating a link is $f$.

In the second stage, the upstream firm decides a linear wholesale price $w$ to supply the input to the firms attending the posted price market and an individual linear wholesale price $w_{i}$ to be offered to each linked downstream firm $i$.

In the third stage, downstream firms decide how many units to buy from the upstream firm and how many units to sell to final consumers. We allow linked firms to attend the posted price market and, therefore, they will make use of the personalized prices only when $w \geq w_{i}$.

We look for the Subgame Perfect Nash Equilibrium of the game solving it by backward induction.

Solving explicitly this game is complex. Moreover, as we show below, in order to obtain the equilibrium distribution of links, which is our main interest, it is enough to solve a simplified version of the game (called Game I) where linked firms do not have the option to be supplied in the posted price market. Very nicely, we will show that there is a strong relationship between the equilibria of Game I and the equilibria of our original game.

In the third stage, as we have a continuum of firms, they behave as price taking firms. On the one hand, linked firm $i$ chooses output $q_{i}$ to maximize its profits:

$$
\pi_{i}=P q_{i}-c_{i} q_{i}-q_{i}^{2}-w_{i} q_{i}
$$


This leads to the following individual supply function for linked firm $i$ :

$$
S_{i}(P)=\frac{P-c_{i}-w_{i}}{2}
$$

On the other hand, the individual supply of a non-linked firm $j$ is similarly obtained and amounts to:

$$
S_{j}(P)=\frac{P-c_{j}-w}{2} .
$$

The market clearing condition is given by:

$$
\int_{N}\left(\frac{P-c_{i}-w}{2}\right) d i+\int_{L}\left(\frac{P-c_{i}-w_{i}}{2}\right) d i=A-P
$$

where $N=\{i \in[0,1] /$ firm $i$ is not linked $\}$ and $L=\{i \in[0,1] /$ firm $i$ is linked $\}$.

We focus on an interior equilibrium in which all downstream firms produce. With some abuse of notation, (1) leads to the following equilibrium price:

$$
P(t, w)=\frac{2 A+n+l+t+w z}{3},
$$

where $z$ is the mass of set $N$ (hence, the mass of set $L$ amounts to $1-z$ ), $n$ and $l$ are defined as $n=\int_{N} c_{i} d i$ and $l=\int_{L} c_{i} d i$ respectively, and $t$ is the aggregate of personalized wholesale prices, $t=\int_{L} w_{i} d i$. Hence, for a given mass of connected and unconnected firms, the equilibrium price depends on the posted price $w$ and on $t$.

In the second stage, and given the set of linked firms, the monopolist chooses the schedule of personalized wholesale prices $\left\{w_{i}\right\}_{L}$ and the posted price $w$ to maximize its profits:

$$
\Pi^{I}\left(\left\{w_{i}\right\}_{L}, w\right)=\int_{N} w\left(\frac{P(t, w)-c_{i}-w}{2}\right) d i+\int_{L} w_{i}\left(\frac{P(t, w)-c_{i}-w_{i}}{2}\right) d i,
$$

where superscript $I$ denotes Game I. These profits can be rewritten as:

$$
\Pi^{I}\left(\left\{w_{i}\right\}_{L}, w\right)=w\left(\frac{P(t, w)-w}{2}\right) z-\frac{w}{2} n+\frac{P(t, w)}{2} t-\int_{L} w_{i}\left(\frac{c_{i}+w_{i}}{2}\right) d i
$$

The first order condition with respect to the posted price is:

$$
\frac{\partial \Pi^{I}\left(\left\{w_{i}\right\}_{L}, w\right)}{\partial w}=\left(\frac{P(t, w)-2 w}{2}\right) z+\frac{w}{6} z^{2}-\frac{n}{2}+\frac{z}{6} t=0,
$$


whereas pointwise maximization with respect to personalized wholesale prices lead to first order conditions:

$$
\frac{\partial \Pi^{I}\left(\left\{w_{i}\right\}_{L}, w\right)}{\partial w_{i}}=\frac{w}{6} z+\frac{1}{6} t+\frac{P(t, w)}{2}-\frac{c_{i}+2 w_{i}}{2}=0
$$

for all $w_{i} \in L$. Aggregating over the first order conditions for the personalized prices we have:

$$
\int_{L} \frac{\partial \Pi^{I}\left(\left\{w_{i}\right\}_{L}, w\right)}{\partial w_{i}} d i=\frac{w z+t+3 P(t, w)}{6}(1-z)-\frac{l+2 t}{2}=0 .
$$

From (4) and (6), we obtain that the optimal posted price is equal to $w^{*}=\frac{1}{2}\left(A-\frac{n}{z}\right)$ and the aggregate of optimal personalized wholesale prices is equal to $t^{*}=\frac{1}{2}((1-z)$ $A-l$ ). Plugging $w^{*}$ and $t^{*}$ into (5) we obtain that the monopolist chooses a personalized wholesale price $w_{i}^{*}=\frac{1}{2}\left(A-c_{i}\right)$ for a connected downstream firm $c_{i}$.

Notice that, due to the linearity of the model, the personalized contract does not depend on the distribution of links. Plugging $w^{*}$ and $t^{*}$ into (1) we get the equilibrium price:

$$
P\left(t^{*}, w^{*}\right)=\frac{1+10 A}{12}
$$

Observe that the equilibrium price does not depend on the distribution of links either. $^{5}$

To guarantee that for any distribution of links all firms produce in equilibrium, we must have $A>\frac{11}{4}$. This guarantees that the most inefficient downstream firm always produces for any level of connected firms.

The equilibrium profits of the upstream firm amounts to:

$$
\Pi^{I}\left(\left\{w_{i}^{*}\right\}_{L}, w^{*}\right)=\frac{3 n^{2}+\left(2 A(A-1)+3 \widehat{l}-\frac{1}{4}\right) z}{24 z},
$$

where $\widehat{l}=\int_{L} c_{i}^{2} d i$.

In the first stage, we have to derive the equilibrium distribution of links depending on whether the links are created by the upstream firm or by downstream firms. We analyze each case in turn.

\footnotetext{
5 Yoshida (2000) considers a more general transformation technology for the inputs. For the particular case of one-to-one relationship between input and output, however, the equilibrium price is the same with and without price discrimination. Hence we obtain that his results extends to any possible level of partial price discrimination.
} 
2.1 The upstream firm chooses the links

We proceed to characterize the first stage equilibrium of Game I. The decisions of the upstream firm are (1) to choose the number of unconnected firms (that amounts to decide the mass z of set $N$ ) and (2) to decide the distribution of connected and unconnected firms (that amounts to the choice of terms $n$ and $\widehat{l}$ in the profit expression).

In the following lemma, we find the distribution of connected firms that maximizes (8), for a given measure $1-z$ of linked firms.

Lemma 1 In Game I, fix the measure $z$ of non-linked firms, then the optimal distribution of links for the upstream firm is such that the set of nonlinked firms is a single interval.

Proof For the sake of simplicity we restrict the set of $L$ sets available to the upstream firm to be countable unions of disjoint sets. ${ }^{6}$ For the distributions not considered in the lemma, there exist numbers $0 \leq a<b<d \leq 1$ and $0<c<d-b$, such that firms in $[a, b] \cup[b+c, d]$ are not connected and the ones in $[b, b+c]$ are connected.

If $\mathrm{z}$ is the measure of unconnected firms and $\mathrm{H}$ is the expected cost of unconnected firms other than the ones in $[a, b] \cup[b+c, d]$, the payoff of the upstream firm can be written as:

$$
\Pi^{I}=\left(H+\int_{a}^{b} c_{i} d i+\int_{b+c}^{d} c_{i} d i\right)^{2}+z \int_{b}^{b+c} c_{i}^{2} d i+\text { constant. }
$$

We show that these distributions are not optimal because the payoff can be increased changing $b$. The first derivative of $\Pi^{I}$ with respect to $b$ yields:

$$
\frac{\partial \Pi^{I}}{\partial b}=\left(H+\int_{a}^{b} c_{i} d i+\int_{b+c}^{d} c_{i} d i\right)\left(b-(b+c)+z\left((b+c)^{2}-b^{2}\right),\right.
$$

which can be rewritten as:

$$
\frac{\partial \Pi^{I}}{\partial b}=-2 c\left(H+\int_{a}^{b} c_{i} d i+\int_{b+c}^{d} c_{i} d i\right)+(2 b+c) c z,
$$

whereas the second derivative is given by:

$$
\frac{\partial^{2} \Pi^{I}}{\partial b^{2}}=2 c^{2}+2 c z>0 .
$$

The convexity of the payoff function implies that these distributions do not maximize the profits of the upstream firm. If we allow the upstream to choose parameter

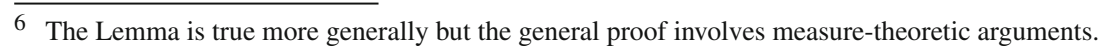


$b$, it will choose either $b=a$ or $b=d-c$ increasing its profits. In any case, the set $[b, b+c]$ will not be any longer an "island" of linked firms. Iterating this process, we will end up with a distribution of linked firms included in the Lemma and, given the convexity of the payoff function, the payoff of the upstream firm increases. Now, in order to check that any distribution in the Lemma is optimal, observe that he payoff of the upstream firm with any of these distributions is:

$$
h(s)=\left(\int_{s}^{z+s} c_{i} d i\right)^{2}\left(\int_{0}^{s} c_{i}^{2} d i+\int_{z+s}^{1} c_{i}^{2} d i\right) z .
$$

We obtain the first derivative:

$$
h^{\prime}(s)=2\left(\int_{s}^{z+s} c_{i} d i\right)(z+s-s)+\left(s^{2}-(z+s)^{2}\right) z .
$$

Rearranging terms, we obtain that the function is constant in $s$ :

$$
h^{\prime}(s)=\left((z+s)^{2}-s^{2}\right) z+\left(s^{2}-(z+s)^{2}\right) z=0 .
$$

Therefore, all the distributions in the Lemma lead to the same payoff.

In order to understand the intuition behind the above result observe that, if all firms were linked, every firm would be charged a personalized price equal to $w_{i}=\frac{A}{2}-\frac{c_{i}}{2}$. Given that connecting firms is costly, a subset of firms will not be linked and they will be charged a price that is an average of their personalized prices. The gain of price discrimination is higher the higher the difference between the personalized prices and the posted price, which is achieved by having nonlinked firms as similar as possible.

For a given mass $1-z$ of linked firms, Lemma 1 gives us all the optimal distributions of links in Game I. All these distributions yield the same profits to the upstream firm. Recall that in Game I a linked firm has not the option to use the posted price. In the original game, linked firms will use personalized prices if they are lower than the posted price, namely, $w^{*}(L) \geq w_{i}^{*}$ for all $i \in L$. This means that the second stage of the original game solves the same problem as Game I with an additional constraint. But this, of course, implies that the upstream firm can not obtain more profits in the original game than in Game I.

Among all equivalent distributions of links in terms of upstream profits, there is only one, $J$, that satisfies the previous constraint. This distribution is the one that links only the most inefficient firms, that is, $J=[z, 1]$. Observe that the highest personalized contract in $J$ is $w_{i}(z)=\frac{1}{2}(A-z)$ is lower than $w^{*}(J)=\frac{1}{2}\left(A-\frac{z}{2}\right)$. This implies that the equilibrium contracts and profits of Game I are also the equilibrium contracts in the original game.

The remaining possible distribution of links in Lemma 1 , have an interval $[0, s]$, with $s>0$, that includes the firm with the lowest cost. For this firm (and for some 
neighborhood of firms with strictly positive mass around 0$)$, the personalized price $w_{i}\left(c_{i}=0\right)=\frac{A}{2}$ would be strictly higher than $w^{*}=\frac{1}{2}\left(A-\frac{n}{z}\right)$; hence, these firms would refuse the personalized price and would attend instead the posted price market. Therefore, $J=[z, 1]$ is the optimal distribution of links for the upstream firm.

For this optimal distribution of links (and assuming there is indeed a positive measure of connected firms, i.e. $z<1$ ), to have all firms producing in equilibrium it is sufficient that $A>\frac{5}{4}$. This guarantees that the most inefficient downstream firm $c_{i}=1$ (that we know it is connected and pays a personalized price $w_{1}^{*}=\frac{1}{2}(A-1)$ ) always produces for any level of connected firms. ${ }^{7}$

Transforming (8) taking into account that only firms in $[z, 1]$ are connected, we can obtain the payoff of the upstream firm in the first stage as a function of $z$, which is given by:

$$
\frac{-\frac{1}{4} z^{3}+\left(2 A(A-1)+\frac{3}{4}\right)}{24}-(1-z) f .
$$

We are now ready to establish the main result of this section.

Proposition 2 If $z_{u}=4 \sqrt{2 f}<1$, downstream firms in $\left[0, z_{u}\right]$ pay a posted price $w=\frac{A}{2}-\sqrt{2 f}$, firms in $\left[z_{u}, 1\right]$ are connected and pay personalized prices $w_{i}=\frac{A}{2}-\frac{c_{i}}{2}$. If $z_{u}=4 \sqrt{2 f} \geq 1$, all firms are served through a posted price $w=\frac{A}{2}-\frac{1}{4}$. In both cases the final price is $\frac{1+10 A}{12}$.

Observe that the size of demand $(A)$ does not affect the set of linked firms. Of course, it affects upstream gains and losses of connecting downstream firms, but in the aggregate these effects cancel out. Notice that creating a link has a direct positive effect of allowing the upstream firm to personalize the contract, which is indeed increasing in $A$. On the other hand, it has an indirect effect because the upstream firm will adjust

7 In the absence of links and whenever $A>2$, the upstream firm chooses the posted price $w^{*}=\frac{1}{2}\left(A-\frac{1}{2}\right)$ and all downstream firms produce $\left(P\left(w^{*}\right)-w^{*}-c_{i}=\frac{1+10 A}{12}-\frac{1}{2}\left(A-\frac{1}{2}\right)-c_{i}=\frac{1}{12}\left(4 A+4-12 c_{i}\right)\right.$ is strictly positive for all of them if $A>2$ ). Total production is just the same as when some of theses firms are connected, $1-P\left(w^{*}\right)=\frac{2 A-1}{12}$.

For $\frac{5}{4}<A<2$, instead, there is more production (and consumer surplus increases) if inefficient firms are connected and offered a personalized price. Without links, all firms are offered the same posted price $w$; the individual supply of a non-linked firm $i$ is $S_{i}(P)=\frac{P-c_{i}-w}{2}$ and the market clearing condition is given by $\int_{0}^{c}\left(\frac{P-c_{i}-w}{2}\right) d i=A-P$. The equilibrium price is equal to $P(A, w, c)=\frac{4 A+c^{2}+c w}{2(2+c)}$, and the cutoff marginal cost $c$ becomes $c(A, w)=\min \{2(\sqrt{1+A-w}-1), 1\}$ and, whenever $c(A, w)<1$, the upstream firm faces total demand $Q(A, w)=\int_{0}^{c}\left(\frac{P(A, w, c)-c_{i}-w}{2}\right) d i=1+d(A, w)-2 \sqrt{d(A, w)}$, where $d(A, w)$ is defined as $d(A, w)=1+A-w$. Maximization of profits $w Q(w)$ leads to $w^{*}=\frac{1}{8}(3+4 A-\sqrt{9+8 A})$. The cutoff marginal cost $c\left(A, w^{*}\right)$ is indeed below one whenever $A<2$, and total production is $Q\left(A, w^{*}\right)=$ $1+d\left(A, w^{*}\right)-2 \sqrt{d\left(A, w^{*}\right)}=\frac{1}{8}(5+4 A+\sqrt{9+8 A})$. Total production is below $\frac{2 A-1}{12}$ whenever $\frac{5}{4}<A<2$, and converges to $\frac{2 A-1}{12}$ as $A$ approaches 2 .

Intuitively, if the upstream firm is restricted to choose only a posted wholesale price, for sufficiently low values of the intercept of demand $A$, inefficient downstream firms are driven out of the market; personalized prices allow the upstream firm to profitably use the capacity of production of inefficient downstream firms, lowering the wholesale price that they are charged. 
the posted price upwards. It turns out that this indirect effect is decreasing in $A$ and it exactly cancels out with the direct effect.

\subsection{Downstream firms choose the links}

First of all, we show that an equilibrium with connected firms is defined by a cut-off value $z$ such that all firms in $[z, 1]$ get connected.

Assume a candidate equilibrium set $L$ of linked firms. Denote by $w_{i}^{+}$and $w^{+}$the equilibrium contracts given this distribution of links. Then, it must be the case that a downstream firm with $\cos t c_{i}$ is connected in equilibrium if and only if:

$$
\begin{aligned}
F\left(L^{+}, w_{i}^{+}, w^{+}\right)= & \left(\frac{P^{*}\left(L^{+}, w_{i}^{+}, w^{+}\right)-w^{+}-c_{i}}{2}\right)^{2} \\
& -\left(\frac{P^{*}\left(L^{+}, w_{i}^{+}, w^{+}\right)-w_{i}^{+}-c_{i}}{2}\right)^{2}+f \leq 0 .
\end{aligned}
$$

This requires that for all $c_{i} \in L^{+}, w^{+}>w_{i}^{+}$.

In other words, a firm $i$ is connected in equilibrium only if its personalized price is lower than the posted price. But then, the maximization program of the upstream firm is such that the restriction that linked firms only use the personalized contract if it offers better terms that the posted market is not binding. This implies that the optimal contracts must be the same as the ones in Game I. They are given by:

$$
w_{i}^{+}=w_{i}^{*}=\frac{A}{2}-\frac{c_{i}}{2} \quad \text { and } \quad w^{+}=w^{*}(L)=\frac{A}{2}-\frac{n}{2 z} .
$$

Plugging the optimal contracts into expression (10), we obtain:

$$
F\left(L^{+}, w_{i}^{*}, w^{*}(L)\right)=\left(\frac{\frac{10 A+1}{12}-\left(\frac{A}{2}-\frac{n}{2 z}\right)-c_{i}}{2}\right)^{2}-\left(\frac{\frac{10 A+1}{12}-A / 2-c_{i} / 2}{2}\right)^{2}+f .
$$

We now check that this function is strictly decreasing in $c_{i}$ :

$$
\begin{aligned}
\frac{\partial F}{\partial c_{i}} & =\left(\frac{1}{8}\right)\left(-A+3 c_{i}-\frac{10 A+1}{6}+4\left(\frac{A}{2}-\frac{n}{2 z}\right)\right) \\
& <\left(\frac{1}{48}\right)\left(-1-4 A+18 c_{i}\right)<0 \quad \text { if } A>5
\end{aligned}
$$

This implies that if (10) is satisfied for a firm with cost parameter $c_{i}$, it must also hold for less efficient firms. In other words, the equilibrium must have a cutoff structure, where only high-cost firms decide to establish a link. 
Next, we have to look for the equilibrium value of $z$. If firms with $i \in[z, 1]$ are connected, the optimal posted price in Game $\mathrm{I}$ is $\frac{A}{2}-\frac{z}{4}$ and it is higher than the personalized price received by any linked firm:

$$
\frac{A}{2}-\frac{z}{4}>\frac{A-z}{2} \geq \frac{A-c_{i}}{2}, \quad \text { for all } i \in[z, 1] .
$$

Then, by using Lemma 2.2, we know that the original game has the same equilibrium contracts as Game I.

Firm $i=z$ must be indifferent between incurring or not the connecting cost. Hence the equilibrium value of $z$ must satisfy:

$$
F\left(1-z, \frac{A-z}{2}, \frac{A}{2}-\frac{z}{4}\right)=\left(\frac{1}{192}\right) z(-2-8 A+15 z)+f=0 .
$$

It has only one solution in $[0,1]$, denoted by $z^{*}$. Then, the equilibrium distribution of links is given in the following proposition.

Proposition 3 If $z_{d}=\frac{4 A+1-\sqrt{(4 A+1)^{2}-2880 f}}{15}<1$, downstream firms in $\left[0, z_{d}\right]$ pay a posted price $w=\frac{A}{2}-\frac{z_{d}}{4}$ and the firms in $\left[z_{d}, 1\right]$ are connected and pay personalized prices $w_{i}=\frac{A}{2}-\frac{c_{i}}{2}$. If $z_{d} \geq 1$, all firms are served through a posted price $w=\frac{A}{2}-\frac{1}{4}$. In both cases the final price is $\frac{1+10 A}{12}$.

We have that the number of links created is decreasing in $f$ and increasing in $A$. Comparing Propositions 2 and 3, we can conclude that more links are created when downstream firms create the links than when the upstream firm creates the links. In the former case, the firms that invest in the link impose a negative externality on the firms that remain in the posted price market, in the form of a higher wholesale price. This leads downstream firms to create too many links. In fact, if they could decide the number of links in order to maximize joint downstream profits, they would create no link at all. In the latter case, the upstream firm takes into account the externality when deciding the number of links to be created. As we have seen, as a result, it creates less links.

Regarding social welfare we study the effect of price discrimination assuming that there is an upstream firm selling the good. It is crucial to notice that total output does not depend on the distribution of links. Then (partial) price discrimination only affects costs. We know that the upstream firm through price discrimination subsidizes inefficient firms which increases total costs. Then welfare will be maximized when price discrimination is forbidden.

\section{The case of endogenous cost}

Up to now, the cost of a link has been assumed to be exogenous. It seems interesting to analyze the case where this cost becomes endogenous. One possibility is that there exists an intermediary in charge of connecting the upstream and downstream firms. 
In this case the cost of the link would be represented by a subscription fee that the intermediary would charge both to the upstream and any downstream firm willing to establish a personal relationship. We assume that the creation of a link between the upstream firm and downstream firm $i$ occurs only when both of them pay the subscription fee.

Let us analyze the following game. First, the intermediary chooses the subscription fee for the upstream firm $\left(s_{u}\right)$ and for downstream firms $\left(s_{d}\right)$. Second, the upstream firm chooses for which downstream firms to pay the subscription fee. Third, each downstream firm decides whether or not to pay the subscription fee. In the fourth stage, the upstream firm sets the supply contracts. Finally, market competition takes place. We solve the game by backward induction.

Stages four and five are like in the previous model. Observe that, for simplicity and in order to avoid coordination failures, we assume that the upstream firm pays the subscription fees before downstream firms. The solution of these two stages is a direct application of the results of the previous sections. Assume that the upstream firm has paid the subscription fee for downstream firms in the set $[z, 1]$. This is the relevant case, because we know that the upstream firm wants to connect inefficient firms. In the third stage, in order to determine which downstream firms will pay the fee, it is useful to recall what would happen in the model where links were decided by downstream firms and $f=s_{d}$ : in this case, firms in the set $\left[z^{d}\left(s_{d}\right), 1\right]$ would be connected. But now we have the additional restriction that the upstream firm has to have paid the subscription fee. Then, the set of downstream firms that will pay the fee in equilibrium is given by $\left[\operatorname{Max}\left\{z^{d}\left(s_{d}\right), z\right\}, 1\right]$.

In order to solve the second stage, we have to recall the result when the upstream chose the links and $f=s_{u}$. It connected the firms in the set $\left[z^{u}\left(s_{u}\right), 1\right]$. But now, the upstream firm has to be sure that the corresponding downstream firms will pay the fee. Then, in equilibrium it will pay the fee for firms in $\left[\operatorname{Max}\left\{z^{u}\left(s_{u}\right), z^{d}\left(s_{d}\right)\right\}, 1\right]$.

In the first stage, the objective of the intermediary firm is given by:

$$
\left(s_{u}+s_{d}\right)\left(1-\operatorname{Max}\left\{z^{u}\left(s_{u}\right), z^{d}\left(s_{d}\right)\right\}\right)
$$

It is easy to see that, in equilibrium, it must be the case that $s_{u}$ and $s_{d}$ are chosen so that $z^{u}\left(s_{u}\right)=z^{d}\left(s_{d}\right)$. The reason is the following: imagine that $z^{u}\left(s_{u}\right)<z^{d}\left(s_{d}\right)$. In this case, the intermediary firm could increase profits by increasing slightly $s_{u}$. Observe that this would not change the number of links created but it would allow the intermediary to obtain more revenues from the upstream firm. Finally, we solve the maximization program of the intermediary making use of $z^{u}\left(s_{u}\right)=z^{d}\left(s_{d}\right)$, and get the equilibrium subscription fees $s_{u}^{*}$ and $s_{d}^{*} \cdot{ }^{8}$ We check that they are positive and

8 The actual values are complex and not very informative. They are given by:

$$
\begin{aligned}
& s_{d}^{*}=\frac{-371-32(-4+A) A+2(23+2 A) \sqrt{(67+8 A(-5+8 A)}}{23328} \\
& s_{u}^{*}=\frac{94+68 A+64 A^{2}-(11+8 A) \sqrt{67+8 A(-5+8 A)}}{11664} .
\end{aligned}
$$


increasing in the size of demand $(A)$. However, $s_{u}^{*}$ is much smaller and less sensitive than $s_{d}^{*}$ to changes in $A$. In particular, $\operatorname{Lim}_{A->\infty}^{s_{d}{ }^{*}}=\infty$ and $\operatorname{Lim}_{A->\infty}^{s_{u}^{*}}=\frac{1}{128}$. The reason of the low upper bound for $s_{u}^{*}$ is that the links that the upstream firm is willing to create do not depend on $A$ and it creates no link whenever $s_{u} \geq \frac{1}{32}$. As the intermediary firm finds profitable to create links it will set the subscription fee at a lower level than this limit. Observe that the profitable side of the market is the downstream sector where the subscription fee grows without bounds. In fact, even the existence of a small transaction cost $(k)$ of collecting the fees of the upstream firm would induce the intermediary firm to provide the connection to the upstream firm for free. A sufficient condition for this to hold is that $k \geq \frac{1}{128}$, which is the upper bound of the revenues obtained from the upstream firm in the model.

Summarizing, we obtain partial price discrimination as the equilibrium outcome of an extended game where the cost of creating links is endogenously created by an intermediary firm. We obtain as before that high cost firms are the ones treated personally. Moreover, we obtain that the burden of the (endogenous) cost of price discrimination mainly falls on the downstream side of the market.

So far we have assumed that the links are costless. If creating a link is costly and the cost is borne by the intermediary, it is direct to see that this cost is passed on to both upstream and downstream firms in the form of higher fees. However, this would not change any of the qualitative results of the paper.

\section{Discussion and conclusion}

The literature on third-degree price discrimination has mainly focused on its effect on social welfare. Profitability of price discrimination was taken for granted given that no cost was associated with it. Our contribution to the literature is to recognize that customizing prices may be costly, which creates an interesting trade-off. The upstream firm, before deciding whether to personalize the price of a customer, has to balance its possible gains with its cost. As a result, he decides to pay the cost for his most valuable customers and charge a uniform price to the rest of firms. We name this situation as partial price discrimination and it encompasses as particular cases those of uniform price and complete price discrimination that have focused the attention of the literature so far.

We have considered a model with an upstream monopolist selling an input to a continuum of heterogeneous downstream firms producing an homogeneous good. We show that, regardless of whether the cost of the links is paid by the upstream firm or downstream firms, inefficient firms receive personalized prices. Furthermore, when the cost of the link is endogenized through an intermediary, we obtain that most of the intermediation profits are obtained from the competitive downstream sector. One is left to wonder whether the results crucially depend on the structure of the upstream and downstream sector. It is straightforward to show that the same results can be obtained if we assume instead that the upstream sector is competitive and we have a monopoly downstream. In this case, however, most of the profits of intermediation are paid by the (competitive) upstream sector. This indicates that the side of the market that bears the cost of intermediation depends on the horizontal level of competition and not on whether it is a buyer or a seller in the input market. 
Open Access This article is distributed under the terms of the Creative Commons Attribution Noncommercial License which permits any noncommercial use, distribution, and reproduction in any medium, provided the original author(s) and source are credited.

\section{References}

Chen Y (2006) Marketing innovation. J Econ Manage Strategy 15(1):101-123

DeGraba P (1990) Input market price discrimination and the choice of technology. Am Econ Rev 80(5):1246-1253

Katz ML (1987) The welfare effects of third-degree price discrimination in intermediate good markets. Am Econ Rev 77(1):154-167

Lafontaine F, Oxley J (2004) International franchising practices in Mexico: do franchisors customize their contracts? J Econ Manage Strategy 13(1):95-123

Lieberman W (1991) Making yield management work for you: ten steps to enhance revenues. Travel, Tourism and Hospitality Bulletin. A.D. Little Inc.

Lieberman W (1993) Debunking the myths of yield management. The Cornell Hotel and Restaurant 34: $34-41$

Liu Q, Serfes K (2004) Quality of information and oligopolistic price discrimination. J Econ Manage Strategy 13(4):671-702

Milliou C, Petrakis E (2004) Business-to-business electronic marketplaces: joining a public or creating a private. Int J Finance Econ 9:99-112

Robinson J (1933) Economics of imperfect competition. MacMillan, London

Schmalensee R (1981) Output and welfare implications of monopolistic third degree price discrimination. Am Econ Rev 71:242-247

Schwartz M (1990) Third-degree price discrimination and output: generalizing a welfare result. Am Econ Rev 80(5):1259-1262

Shapiro C, Varian H (1999) Information rules: a strategic guide to the network economy. Harvard Business School Press, Cambridge, MA

Varian H (1980) Price discrimination and Social Welfare. Am Econ Rev 75:870-875

Yoshida Y (2000) Third-degree price discrimination in input markets: output and welfare. Am Econ Rev 90(1):240-246 